\title{
Assessment of Mechanical Properties and Damage of High Performance Concrete Subjected to Magnesium Sulfate Environment
}

\author{
Sheng Cang, ${ }^{1,2}$ Xiaoli Ge, ${ }^{3}$ and Yanlin Bao ${ }^{2}$ \\ ${ }^{1}$ Ningbo City College of Vocational Technology, Ningbo 315100, China \\ ${ }^{2}$ Department of Mechanics and Engineering Science, Ningbo University, Ningbo 315211, China \\ ${ }^{3}$ Jiangsu Testing Center for Quality of Construction Engineering Co., Ltd., Nanjing 210028, China \\ Correspondence should be addressed to Sheng Cang; cangsheng@nbcc.cn
}

Received 5 April 2017; Revised 20 July 2017; Accepted 10 August 2017; Published 28 September 2017

Academic Editor: Frederic Dumur

Copyright (C) 2017 Sheng Cang et al. This is an open access article distributed under the Creative Commons Attribution License, which permits unrestricted use, distribution, and reproduction in any medium, provided the original work is properly cited.

\begin{abstract}
Sulfate attack is one of the most important problems affecting concrete structures, especially magnesium sulfate attack. This paper presents an investigation on the mechanical properties and damage evolution of high performance concrete (HPC) with different contents of fly ash exposure to magnesium sulfate environment. The microstructure, porosity, mass loss, dimensional variation, compressive strength, and splitting tensile strength of HPC were investigated at various erosion times up to 392 days. The ultrasonic pulse velocity (UPV) propagation in HPC at different erosion time was determined by using ultrasonic testing technique. A relationship between damage and UPV of HPC was derived according to damage mechanics, and a correlation between the damage of HPC and erosion time was obtained eventually. The results indicated that (1) the average increasing amplitude of porosity for HPCs was 34.01\% before and after exposure to magnesium sulfate solution; (2) the damage evolution of HPCs under sulfate attack could be described by an exponential fitting; (3) HPC containing $20 \%$ fly ash had the strongest resistance to magnesium sulfate attack.
\end{abstract}

\section{Introduction}

Nowadays, high performance concrete (HPC) is increasingly being used in the field of construction engineering. However, these engineering structures are regularly subjected to aggressive environment. Sulfates, as highly soluble salts, are considered to be one of the main problems affecting concrete structures. Sulfate attack is generally leading to the volume change and cracking, which results in concrete deterioration. In addition, sulfates are widespread in environment, such as underground water, soil, sea water, or industrial waste water [1]. What is more, magnesium sulfate $\left(\mathrm{MgSO}_{4}\right)$ has the fastest, most severe effects on concrete [2]. Hekal et al. [3] have testified that magnesium sulfate is more severe than sodium sulfate concerning the influence on the properties of concrete. The chemical reactions between concrete and magnesium sulfate are summarized as follows: (1) the sulfate ion $\left(\mathrm{SO}_{4}{ }^{2-}\right)$ reacts with the aluminate and portlandite to form gypsum and ettringite, respectively; (2) the magnesium ion $\left(\mathrm{Mg}^{2+}\right)$ may react with hydroxyl ion $\left(\mathrm{OH}^{-}\right)$to form brucite $\left[\mathrm{Mg}(\mathrm{OH})_{2}\right]$ or the magnesium can partly replace the calcium in calcium silicate hydrate $(\mathrm{C}-\mathrm{S}-\mathrm{H})$. Therefore, the magnesium silicate hydrate $(\mathrm{M}-\mathrm{S}-\mathrm{H})$ that has no binding properties can be formed in the second reaction, and thus the hydrated paste becomes soft and incoherent [4-6].

Up to now, the effects of magnesium sulfate on ordinary concrete have been studied extensively, and there are a lot of investigations conducted into these effects [7-11]. The study on the impact of fly ash on the sulfate resistance properties by Sumer [8] has indicated that the addition of fly ash can significantly increase the resistance to magnesium sulfate attack. The investigation by Chousidis et al. [9] has shown that the durability of concrete can be improved by adding fly ash with high $\mathrm{SO}_{3}$ and free $\mathrm{CaO}$ contents, but the mechanical properties of concrete can be reduced due to the addition of fly ash with significant amounts of clay 
minerals. Furthermore, the use of fly ash is conducive to resisting the magnesium sulfate attack into concrete, because the microstructure of concrete becomes more compact due to the pozzolanic reaction [12]. Mostofinejad et al. [10] have carried out a research on the influence of magnesium sulfate concentration on durability of concrete. The results suggested that the $5 \%$ magnesium sulfate solution is considered to be the most deteriorating environment from the compressive strength reduction viewpoint, while the $14.7 \%$ magnesium sulfate solution is observed as the most severe environment from expansion aspect. However, the composition of HPC is usually different from that of ordinary concrete, and then the behavior of HPC under magnesium sulfate attack may be different from that of ordinary concrete.

As a new construction and building material with various excellent properties, HPC has been widely used in modern concrete structures, while information on the behavior of HPC under magnesium sulfate attack is rather limited and needs to be updated. Uysal and Sumer [13] have presented an experimental investigation on the influence of fly ash on durability of self-consolidating concrete under magnesium sulfate attack, and the results indicated that the addition of fly ash can substantially improve the resistance of selfconsolidating concrete against magnesium sulfate attack. Another study concerning the long-term performance of self-consolidating concrete under magnesium sulfate attack by Siad et al. [1] has shown that the resistance of selfconsolidating concrete under magnesium sulfate attack can be improved due to the addition of natural pozzolan. Silica fume is also used as supplementary cementitious material for the production of HPC, because of its pozzolanic reactivity and microfiller effect. In addition, the fluidity of fresh concrete can be improved due to the addition of silica fume, which may be caused by the dispersing power of the plasticizer coupled with silica fume particle packing between cement grains displacing water or by a ball-bearing effect of silica spheres [14]. However, Behfarnia and Farshadfar [15] have pointed out that silica fume has negative effect on durability of self-consolidating concrete subjected to magnesium sulfate attack, and the debility in specimens containing silica fume is because of formation of magnesium silicate hydrate $(\mathrm{M}-\mathrm{S}-\mathrm{H})$, a nonadherent substance, in such kind of concrete. Harbec et al. [16] have carried out an investigation on mechanical and durability properties of HPC, and the findings demonstrated that the pozzolanic reaction of glass fume contributes to controlling the expansion of HPC due to sulfate attack. In addition, it has been testified that the deterioration of concrete under sulfate attack is affected by many parameters, such as sulfate concentration [10], water to binder ratio [17, 18], participant cation [3, 19-21], temperature [22], $\mathrm{pH}$ [23], and even specimen's size [24].

The study aims to design a new kind of HPC that has characteristics of both high strength concrete and selfconsolidating concrete, based on which the mechanical properties and damage evolution of HPC with different contents of fly ash under magnesium sulfate attack were comprehensively investigated. To this end, the porosity, mass loss, dimensional variation, compressive strength, and splitting tensile strength of HPC were studied at various erosion time up to 392 days.
TABLE 1: Chemical composition and physical properties of cement and mineral admixtures.

\begin{tabular}{lccc}
\hline Materials & Cement & Fly ash & Silica fume \\
\hline Chemical composition & \multicolumn{3}{c}{ Weight percentage (\%) } \\
$\mathrm{CaO}$ & 64.70 & 8.38 & 0.77 \\
$\mathrm{SiO}_{2}$ & 20.40 & 47.96 & 96.18 \\
$\mathrm{Al}_{2} \mathrm{O}_{3}$ & 4.70 & 30.46 & 0.96 \\
$\mathrm{Fe}_{2} \mathrm{O}_{3}$ & 3.38 & 5.91 & 0.85 \\
$\mathrm{MgO}$ & 0.87 & 2.60 & 0.74 \\
$\mathrm{SO}_{3}$ & 1.88 & 1.32 & 0.50 \\
$\mathrm{~K}_{2} \mathrm{O}$ & 0.83 & 1.61 & \\
$\mathrm{Na}_{2} \mathrm{O}$ & & 1.76 & \\
Loss on ignition & 3.24 & & \\
$\mathrm{Physical}$ properties & & & \\
Specific gravity & 3.15 & 2.31 & 2.22 \\
Specific surface (m & \\
28 d Compressive strength $(\mathrm{MPa})$ & 62.8 & & \\
\hline
\end{tabular}

In addition, the ultrasonic pulse velocity (UPV) propagation in HPC at different erosion time was determined via ultrasonic testing technique. According to damage mechanics, a relationship between damage and UPV of HPC was derived, and a correlation between the damage of HPC and erosion time was obtained eventually.

\section{Materials}

2.1. Cement and Mineral Admixtures. Fly ash and silica fume were used as mineral admixtures in the study. The chemical composition and physical properties of cement and mineral admixtures are shown in Table 1 . Note that the fly ash can be graded Class I (equivalent to ASTM C 618 Class F), according to the Chinese standard GB/T 1596-2005. The added silica fume was mainly used to improve the fluidity of the fresh HPC in the work.

2.2. Aggregates. Natural river sand with a maximum size of $4 \mathrm{~mm}$ was used as fine aggregate, and the specific gravity and water absorption of the aggregate were 2.63 and $1.36 \%$, respectively. Crushed limestone aggregate with a maximum size of $16 \mathrm{~mm}$ was utilized as coarse aggregate, and the specific gravity and water absorption of the aggregate were 2.82 and $0.45 \%$, respectively.

2.3. Superplasticizer. A superplasticizer of polycarboxylate obtained from local supplier was used to gain a satisfactory fluidity of HPC. Solid content and water-reducing rate of the superplasticizer were $36.0 \%$ and $33.9 \%$, respectively.

2.4. Mix Proportions of HPC. The mixtures of HPC used in the study are shown in Table 2.

According to the mix proportions shown in Table 2, the cubic (size: $100 \times 100 \times 100 \mathrm{~mm}$ ) and prismatic (size: $70 \times 70$ $\times 280 \mathrm{~mm}$ ) specimens of HPC were cast. The specimens were covered with plastic sheets after casting and were cured 24 
TABLE 2: Mix proportions and fresh properties of HPC.

\begin{tabular}{lcccc}
\hline Mixture & HPC0 & HPC1 & HPC2 & HPC3 \\
\hline Cement $\left(\mathrm{kg} / \mathrm{m}^{3}\right)$ & 530 & 477 & 424 & 371 \\
Fly ash $\left(\mathrm{kg} / \mathrm{m}^{3}\right)$ & 0 & 53 & 106 & 159 \\
Silica fume $\left(\mathrm{kg} / \mathrm{m}^{3}\right)$ & 20 & 20 & 20 & 20 \\
Water $\left(\mathrm{kg} / \mathrm{m}^{3}\right)$ & 160 & 160 & 160 & 160 \\
Fine aggregate $\left(\mathrm{kg} / \mathrm{m}^{3}\right)$ & 477 & 477 & 477 & 477 \\
Coarse aggregate $\left(\mathrm{kg} / \mathrm{m}^{3}\right)$ & 1213 & 1213 & 1213 & 1213 \\
Superplasticizer $\left(\mathrm{kg} / \mathrm{m}^{3}\right)$ & 7.50 & 7.00 & 6.85 & 6.80 \\
Air content $(\%)$ & 4.6 & 4.4 & 4.2 & 4.1 \\
Slump flow $(\mathrm{mm})$ & 585 & 598 & 607 & 616 \\
\hline
\end{tabular}

hours at ambient condition, after which point the specimens were demolded. And then the specimens were placed into a curing room for curing over a span of 28 days with a temperature range of $21 \pm 1^{\circ} \mathrm{C}$ and relative humidity of above 95\%. 90 cubic and 3 prismatic specimens were prepared for each mixture.

\section{Experimental}

3.1. Wetting-Drying Test. The medium used for immersion was $10 \%$ magnesium sulfate solution, and the temperature of the solution was maintained at $21 \pm 1^{\circ} \mathrm{C}$. The $\mathrm{pH}$ of the sulfate solution was holding in the range of $6.0-8.0$ by adding an appropriate amount of sulfate acid solution $\left(0.1 \mathrm{~N} \mathrm{H}_{2} \mathrm{SO}_{4}\right)$. In addition, the magnesium sulfate solution was renewed every 56 days. The wetting-drying test was conducted in accordance with Chinese standard GB/T 50082-2009, but the variation of the experimental method was arranged in order to reduce the effects of high temperature drying. The revised wetting-drying test was shown as follows: the specimens were immersed in 10\% magnesium sulfate solution for 7 days, and then they were taken out from their solution tank for 7-day natural drying (at ambient temperature). After this drying process the specimens were immersed in sulfate solution again. This wetting-drying cycle was repeated for 392 days.

3.2. Microstructure. In order to study the microstructural evolution in HPCs before and after exposure to sulfate solution, the microstructure of HPCs was detected by utilizing a FEI 3D environmental scanning electronic microscopy (ESEM), and the micrographs of HPC2 were taken at different erosion times.

3.3. Porosity. To investigate the porosity of HPCs before and after exposure to sulfate solution, the porosity of HPC with different contents of fly ash was determined quantitatively by a Micromeritics AutoPore IV 9510 mercury intrusion porosimetry (MIP). It should be highlighted that the specimen used for MIP test was mortar of HPC, and the coarse aggregate of HPC was removed during the process of specimen preparation.
3.4. Mass Loss. In order to study the mass evolution of HPCs before and after exposure to sulfate solution, the mass of HPC with different contents of fly ash was measured by a high precision electronic balance with a sensitivity of $0.001 \mathrm{~g}$ at various erosion time. The mass loss ratio $\alpha$ of HPC can be calculated by the equation as follows:

$$
\alpha=\frac{\left(m_{0}-m_{e}\right)}{m_{0}} \times 100,
$$

where $m_{0}$ is the initial mass and $m_{e}$ is the mass of HPC after exposure to sulfate solution.

3.5. Dimensional Variation. To investigate the dimensional variation of HPCs before and after exposure to sulfate solution, the length of HPC with different contents of fly ash was determined via a high accuracy digital length comparator with a precision of $0.001 \mathrm{~mm}$. The expansion ratio $\beta$ of HPC can be calculated by

$$
\beta=\frac{\left(l_{e}-l_{0}\right)}{l_{0}} \times 100,
$$

where $l_{0}$ is the initial length and $l_{e}$ is the length of HPC after exposure to sulfate solution.

\subsection{Mechanical Strength}

3.6.1. Compressive Strength. A universal testing machine was utilized to measure the compressive strength of HPC with different contents of fly ash at various erosion times. The loading rate was set as $0.30 \mathrm{MPa} / \mathrm{s}$ in the compressive test.

3.7. Splitting Tensile Strength. The splitting tensile strength of each mixture at different erosion time was determined by the universal testing machine equipped with a splitting tensile setup at a loading rate of $0.03 \mathrm{MPa} / \mathrm{s}$.

It should be noted that the compressive strength and splitting tensile strength of HPC were measured in accordance with the Chinese standard GB/T 50081-2002, and the cubic specimens were also used in recent published paper for splitting tensile strength of sacrificial concrete [25].

3.8. UPV Test. The experiment on UPV in the study was conducted according to literature [26]. In the actual measuring procedure, the experiment on UPV was implemented according to CECS02-88 [27]. The specific parameters of ultrasonic inspection instrument are presented in Table 3.

3.9. Damage. When HPC is exposed to sulfate solution, damage is initiated in it. The damage leads to a variation in UPV propagation through HPC. According to damage mechanics, the relationship between damage and Young's modulus can be expressed as [28]

$$
D=1-\frac{E_{e}}{E_{0}},
$$


TABLE 3: Specific parameters of ultrasonic inspection instrument.

\begin{tabular}{lccc}
\hline Transmitting voltage & Transmitting pulse width & Amplifier gain & Sampling period \\
\hline $1000 \mathrm{~V}$ & $0.08 \mathrm{~ms}$ & $82 \mathrm{~dB}$ & $0.4 \mathrm{~ms}$ \\
\hline
\end{tabular}

where $D$ is damage, $E_{e}$ is Young's modulus at different erosion time, and $E_{0}$ is initial Young's modulus.

Supposing that HPC is homogeneous material, Young's modulus $E$ correlates its UPV $V$, and their relationship is shown as follows:

$$
V=\sqrt{\frac{E(1-v)}{[\rho(1-2 v)(1+v)]}}
$$

where $\rho$ is the density of HPC and $v$ is Poisson's ratio.

Assuming that sulfate attack has a negligible effect on the Poisson's ratio of HPC. According to (4), then

$$
\begin{aligned}
& E_{0}=\frac{\left[\rho_{0}(1-2 v)(1+v) V_{0}^{2}\right]}{(1-v)}, \\
& E_{e}=\frac{\left[\rho_{e}(1-2 v)(1+v) V_{e}^{2}\right]}{(1-v)} .
\end{aligned}
$$

Substituting (5) into (3), the damage expression of HPC can be obtained:

$$
D=1-\left(\frac{\rho_{e}}{\rho_{0}}\right) \times\left(\frac{V_{e}}{V_{0}}\right)^{2}
$$

where $\rho_{0}$ and $\rho_{e}$ are density of HPC before and after exposure to sulfate solution, respectively. $V_{0}$ and $V_{e}$ are UPV of HPC before and after exposure to sulfate solution, respectively.

The density of HPC before exposure to sulfate solution $\rho_{0}$ was determined according to the Chinese standard GB/T 50080-2002 and can be expressed as

$$
\rho_{0}=\frac{m_{0}}{t_{0}}=\frac{m_{0}}{a^{3}}
$$

where $m_{0}$ is the initial mass, $t_{0}$ is the initial volume, and $a=$ $100 \mathrm{~mm}$.

Thus, the density of HPC after exposure to sulfate solution $\rho_{e}$ can be calculated from the following equation:

$$
\rho_{e}=\frac{m_{e}}{t_{e}}=\frac{(1-\alpha) m_{0}}{[a(1+\beta)]^{3}}=\frac{(1-\alpha) \rho_{0}}{(1+\beta)^{3}} .
$$

Consequently, the damage of HPC after exposure to sulfate solution can be calculated through (6), since the density and UPV of HPC before and after exposure to sulfate solution can be obtained via experiment.

It should be stressed that the cubic (size: $100 \times 100 \times$ $100 \mathrm{~mm}$ ) specimens were used for mass loss, compressive strength, splitting tensile strength, and UPV experiments, and the prismatic (size: $70 \times 70 \times 280 \mathrm{~mm}$ ) specimens were utilized for dimensional variation experiment. In addition, 3 replicate measurements were carried out on the porosity, mass loss, dimensional variation, compressive strength, splitting tensile strength, and UPV experiments at various erosion time, and only the average values were reported so as to improve the accuracy of experimental results. The ESEM test of HPCs was carried out at 0 day, 84 days, 224 days, and 392 days, but the porosity, mass loss, dimensional variation, compressive strength, splitting tensile strength, and UPV experiments were performed at 0 day and every 28 days until 392 days.

\section{Results and Discussion}

4.1. Microstructure. ESEM investigations illustrated vivid variations in the microstructure of HPC at different erosion time. Figure 1 presents the ESEM micrographs of HPC2 before and after exposure to sulfate solution. Note that the green square in Figure 1 was enlarged to show details and was presented in its right side and that energy dispersive spectrometer (EDS) analysis was carried out on the blue square in right micrographs.

As shown in Figure 1, the matrix of HPC2 before exposure to sulfate solution presented a continuous microstructure with few microcracks, and the microcracks were due to sample making. A small amount of microcracks was observed at 84 days, and ettringite was found in the microcracks. The main elemental compositions of EDS area for HPC2 at 84 days were $\mathrm{C}, \mathrm{O}, \mathrm{Mg}, \mathrm{Si}, \mathrm{S}, \mathrm{Ca}$, and $\mathrm{Pt}$, and their weight percent was $6.93 \%, 17.77 \%, 0.41 \%, 4.04 \%, 1.06 \%, 17.00 \%$, and $50.91 \%$, respectively, the result of which indicated that the material in the blue square was ettringite. The ettringite filled the cracks in HPC2 at this erosion time, which resulted in the decrease of its porosity. A fairly large number of microcracks emerged with the erosion time up to 224 days. The main elemental compositions of EDS area for HPC2 at 224 days were $\mathrm{C}, \mathrm{O}, \mathrm{Mg}, \mathrm{Si}, \mathrm{S}, \mathrm{Ca}$, and $\mathrm{Pt}$, and their weight percent was $8.24 \%, 16.56 \%, 0.10 \%, 15.59 \%, 0.78 \%, 13.80 \%$, and $43.62 \%$, respectively, the result of which suggested that the material in the blue square was also ettringite. The ettringite was so much as to cause the expansion of HPC2 at 224 days. Connected cracks spread all over the specimen at 392 days, and the ettringite led to the cracking of HPC2. The main elemental compositions of EDS area for HPC2 at 392 days were C, O, $\mathrm{Mg}, \mathrm{Si}, \mathrm{S}, \mathrm{Ca}$, and $\mathrm{Pt}$, and their weight percent was $21.70 \%$, $22.54 \%, 0.48 \%, 3.20 \%, 0.31 \%, 11.10 \%$, and $39.39 \%$, respectively, the result of which indicated that the material in the blue square was also ettringite. The microstructure evolution of HPC2 under sulfate attack was in line with the results of Siad et al. [1].

4.2. Porosity. The porosity of HPCs at different erosion time is shown in Figure 2.

As seen in Figure 2, the porosity of HPCs decreased slowly before a sharp rise with the increase of erosion time, 

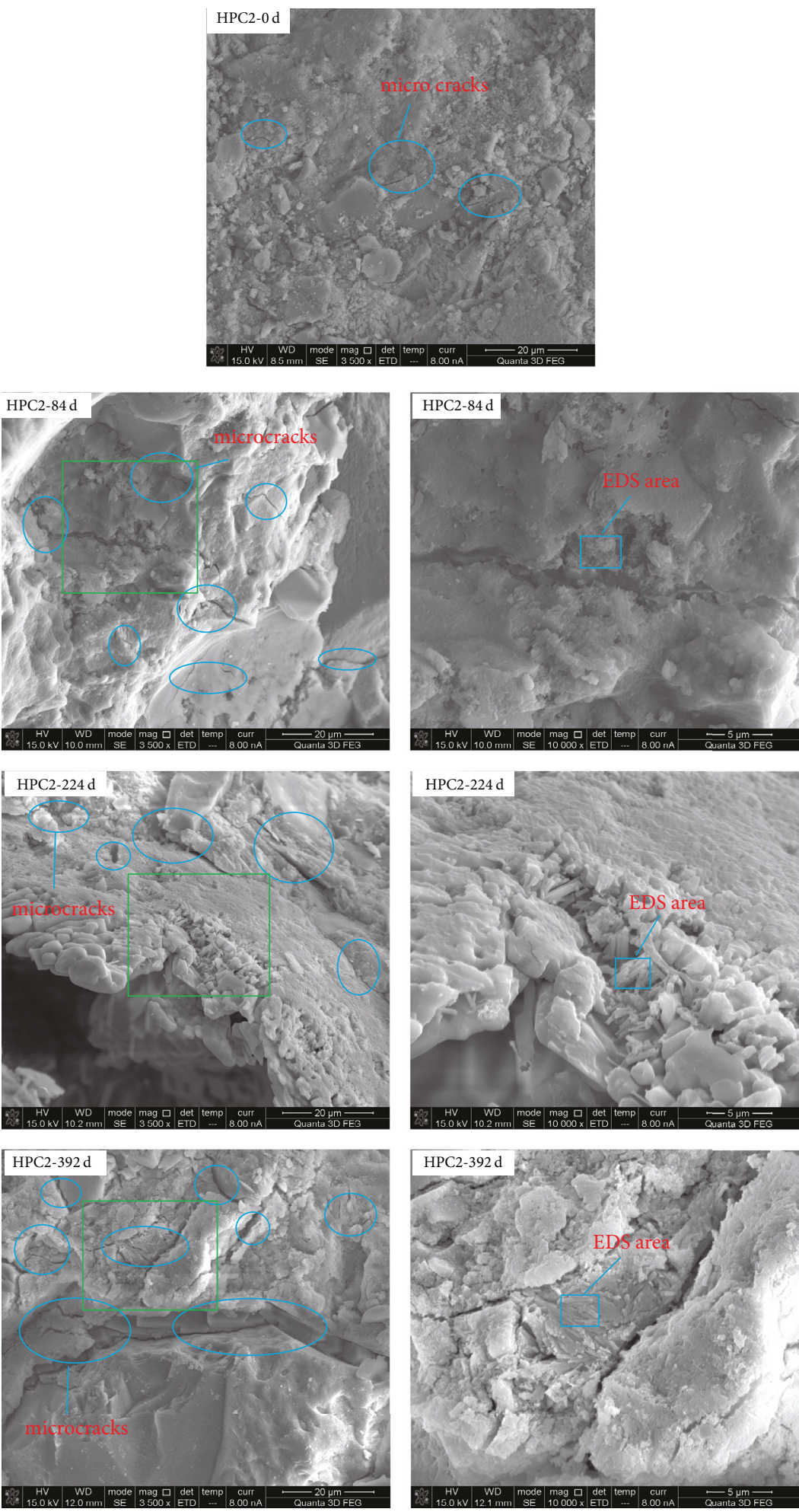

FIGURE 1: ESEM micrographs of HPC2 before and after exposure to sulfate solution.

and the porosity reached the minimum value at 84 (HPC3) or 112 (HPC0, HPC1, and HPC2) days, which meant that sulfate attack contributed to improving the microstructure of HPCs in the early stage (from 0 to 84 or 112 days). The decrease of porosity could be due to the fact that the HPCs absorbed water which resulted in further hydration of the cement and that a small amounts of reaction products between sulfate solution and HPCs filled cracks. The increased porosity could be attributed to the inner expansion of HPCs under sulfate attack. Between 0 and 392 days, the porosity increasing 


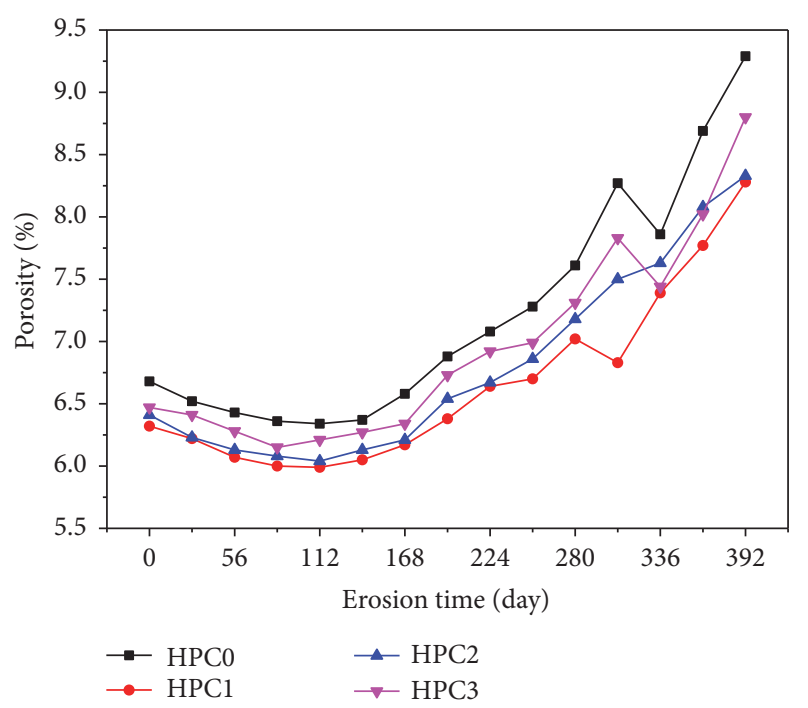

FIgure 2: Porosity of HPCs at different erosion time.

amplitudes of HPC0, HPC1, HPC2, and HPC3 were 39.07\%, $31.01 \%, 29.95 \%$, and $36.01 \%$, respectively, which indicated that the average increasing amplitude of porosity for HPCs was $34.01 \%$ before and after exposure to $10 \%$ magnesium sulfate solution.

In general, the porosity of HPCs with fly ash (HPC1, HPC2, HPC3) was lower than that of HPC without fly ash (HPC0), which was mainly due to pozzolanic effect and microfiller effect of fly ash [29]. On the one hand, the microheads in fly ash could disperse well in concrete, and combined firmly with gel produced in cement hydration, and hence the matrix of concrete could be improved. On the other hand, the gel produced from pozzolanic action could fill in the capillary pore in concrete, which could effectively reduce the porosity of concrete. In addition, the porosity of HPC0 was the highest, followed by HPC3, HPC2, and HPC1, respectively, which suggested that $\mathrm{HPCl}$ had the strongest resistance to magnesium sulfate attack in terms of porosity.

4.3. Mass Loss. The mass loss ratio of HPCs before and after exposure to sulfate solution is presented in Figure 3.

As illustrated in Figure 3, the mass loss ratio of HPCs decreased firstly and then increased with the increment of erosion time, and a minimum value was reached at 84 days. This changing trend was accordant well with that of the porosity (Figure 2). Between 0 and 224 days, the mass loss ratio was negative, which indicated that the mass of HPCs was increased during this time. The phenomenon of mass gain for HPCs is in line with the results of high strength self-consolidating concrete under magnesium sulfate attack [1]. The mass gain could be due to water filling cracks, and to the water used to precipitate the hydrated phase, such as ettringite [30]. The mass loss ratio of HPCs, as a whole, was about between $-0.25 \%$ and $1.60 \%$.

After 336 days, the mass loss ratio of HPCs was increased significantly, which suggested that there was a sharp rise in the degree of deterioration in HPCs. Furthermore, the

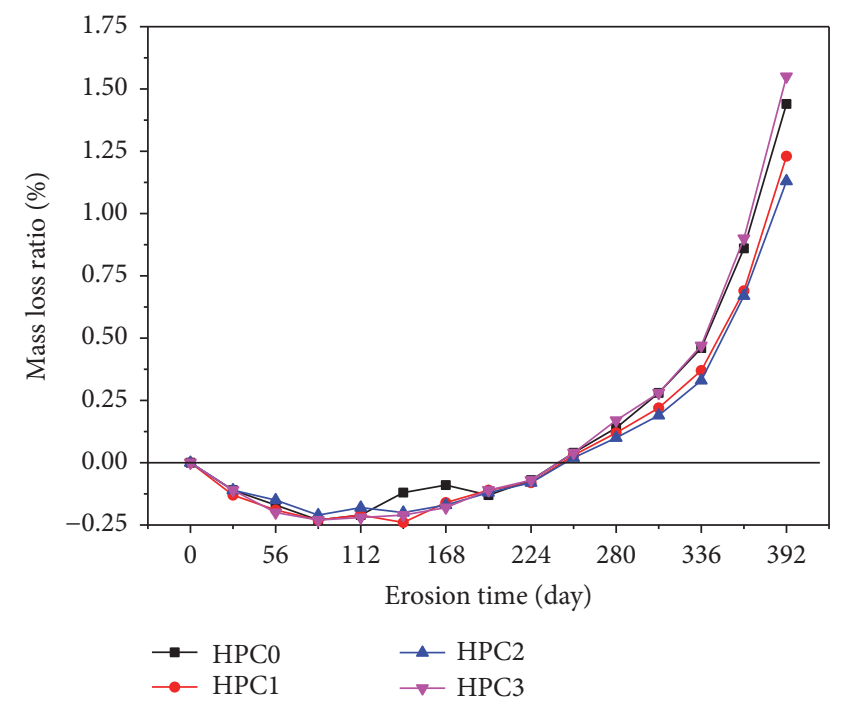

Figure 3: Mass loss ratio of HPCs before and after exposure to sulfate solution.

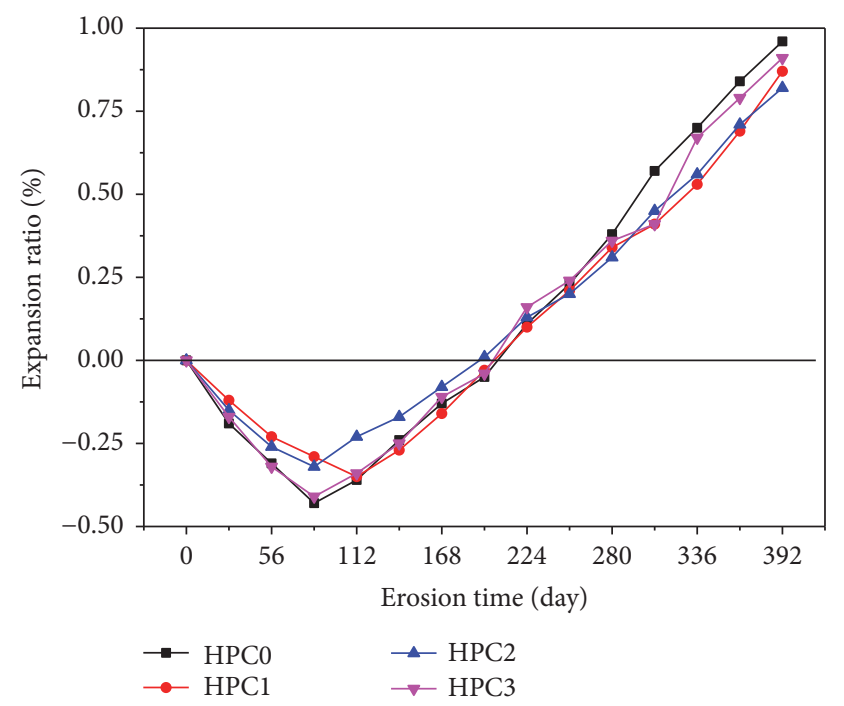

FIGURE 4: Expansion ratio of HPCs at various erosion time.

mass loss ratio of HPC2 was the lowest after 252 days, which indicated that this kind of HPC had the strongest resistance to magnesium sulfate attack in terms of mass loss ratio. It was worth noting that the mass loss ratio of HPC3 was higher than that of HPC0 after 280 days, which demonstrated that the sulfate attack resistance of HPC3 was even weaker than that of HPC0. That is, with this content (30\%) of fly ash, the sulfate attack resistance of HPC could be decreased slightly.

4.4. Dimensional Variation. The expansion ratio of HPCs at various erosion time is shown in Figure 4.

As seen in Figure 4, the expansion ratio of HPCs decreased quickly and then increased rapidly with the increase of erosion time, and the expansion ratio reached the minimum value at 84 (HPC0, HPC2, and HPC3) or 112 (HPC1) days, the changing trend of which was matched 
rather well with that of the porosity (Figure 2). Between 0 and 196 days, the expansion ratio was negative except for HPC2 at 196 days, which was attributed to shrinkage of HPCs. This phenomenon of shrinkage for HPCs is consistent with the results of high strength self-consolidating concrete under magnesium sulfate attack [1]. The shrinkage of HPCs may be due to their autogenous shrinkage at early erosion time. The autogenous shrinkage of HPCs is caused by further hydration of cement and pozzolanic reactions of fly ash and silica fume. Overall, the expansion ratio of HPCs was approximately between $-0.45 \%$ and $0.96 \%$. The absence or the low expansion might be interpreted by the low value water to binder ratio of HPCs. According to Maltais et al. [31], a reduction of water to binder ratio contributes to decreasing the transport properties of the material and thus limits the extent of deterioration. In addition, Neville [32] also pointed out that in high performance concrete there is limited pore space to accommodate the products of reactions with sulfate, namely, $\mathrm{M}-\mathrm{S}-\mathrm{H}$, and gypsum that partly result in expansion.

After 280 days, the expansion ratio of HPCs with fly ash (HPC1, HPC2, and HPC3) was lower than that of HPC without fly ash (HPCO), which indicated that the sulfate attack resistance of HPC could be improved by adding fly ash. And this result was in line with published literature $[9,13]$. In particular, the expansion ratio of HPC2 was the lowest at 392 days. That meant this kind of HPC (HPC2) had the strongest resistance to magnesium sulfate attack in terms of expansion ratio, the result of which was accordant with that of mass loss ratio (Figure 3 ).

4.5. Compressive Strength. The compressive strength of HPCs before and after exposure to magnesium sulfate solution is presented in Figure 5.

As illustrated in Figure 5, the compressive strength of HPCs increased firstly and then decreased with the increment of erosion time, and a maximum value was reached at 84 days. An investigation by Acharya and Patro [11] has also found that the compressive strength of concrete under sulfate attack increases firstly and then decreases with the increase of erosion time, although the compressive strength of concrete is only determined at 28,91 , and 180 days in the literature. Between 0 and 84 days, there was a slow increase in the compressive strength of HPCs, after that the compressive strength decreased at a slower speed (compared to its increase) until 168 days, while the compressive strength was falling rapidly after 196 days. This result was in line with the changing trend of porosity during the same erosion time. The increase of compressive strength could be attributed to the fact that the HPCs absorbed water which resulted in further hydration of the cement and that a small amounts of reaction products between sulfate solution and HPCs filled cracks. The decrease of compressive strength was due to expansion, cracking, and the formation of $\mathrm{M}-\mathrm{S}-\mathrm{H}$. Expansion and cracking generally resulted from expansive forces generated by sulfate reacting with the calcium aluminum hydrates to form ettringite [33]. The formation of $\mathrm{M}-\mathrm{S}-\mathrm{H}$ was because the magnesium could partly replace the calcium in $\mathrm{C}-\mathrm{S}-\mathrm{H}[6]$.

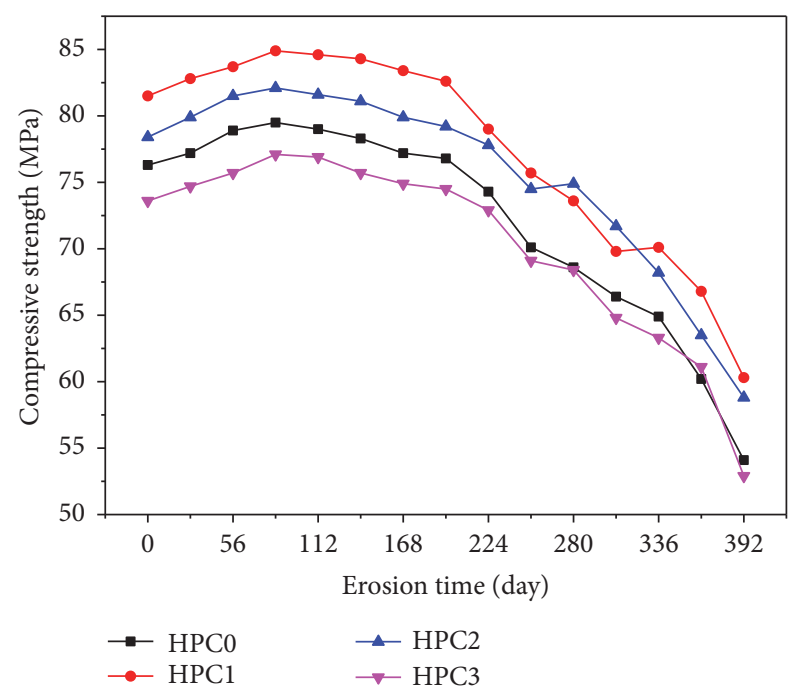

FIGURE 5: Compressive strength of HPCs before and after exposure to sulfate solution.

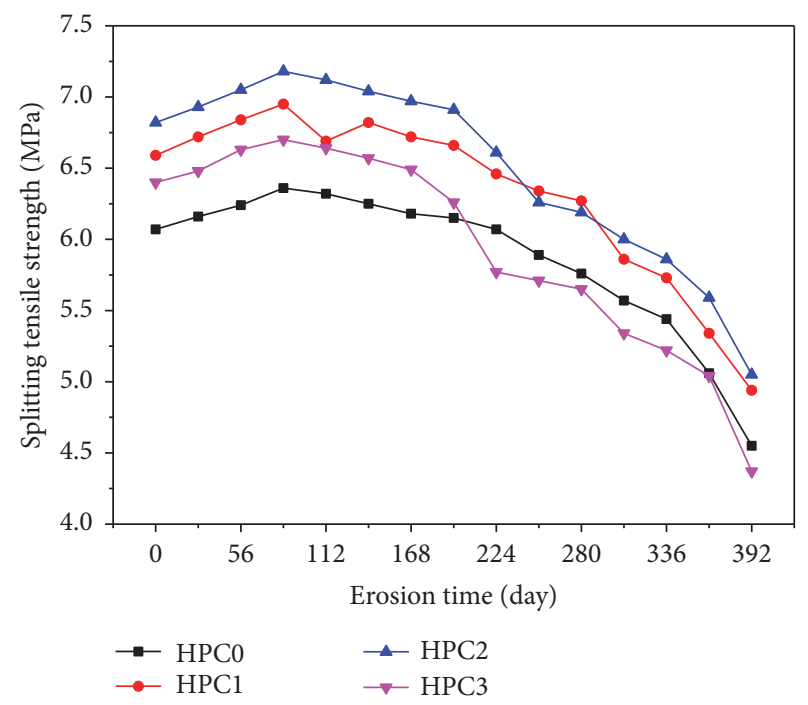

FIGURE 6: Splitting tensile strength of HPCs at different erosion time.

The cracking, in turn, made it easy to transport sulfate ions into concrete, which accelerated the deterioration of HPCs.

The compressive strength of $\mathrm{HPCl}$, on the whole, was the highest before and after exposure to magnesium sulfate solution, which indicated that this kind of HPC had the strongest resistance to magnesium sulfate attack in terms of compressive strength. In addition, the compressive strength of HPC3 was lower than that of HPC0, which demonstrated that the sulfate attack resistance of HPC3 was lower than that of HPC0. That is, with this content (30\%) of fly ash, the compressive strength of HPC could be reduced slightly, which was consistent with that of mass loss ratio (Figure 3).

4.6. Splitting Tensile Strength. The splitting tensile strength of HPCs at different erosion time is shown in Figure 6. 


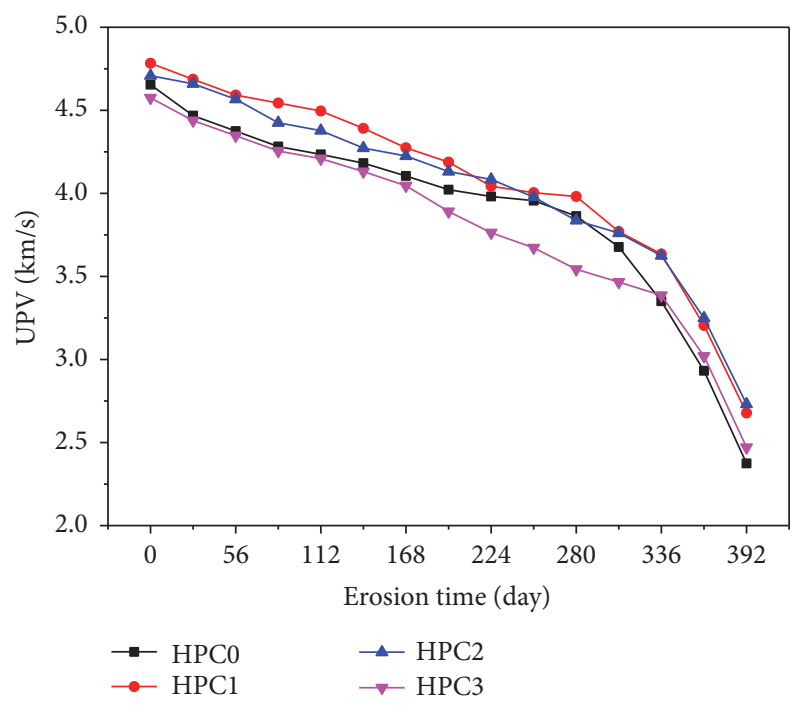

FIgURE 7: UPV of HPCs before and after exposure to sulfate solution.

As shown in Figure 6, the splitting tensile strength of HPCs increased firstly and then decreased with the increase of erosion time, and a maximum value was reached at 84 days. This changing trend was in agreement with that of flexural strength in previous study [11], although the flexural strength of concrete is simply measured at 28, 91, and 180 days in the paper. There was a slow increase in the splitting tensile strength of HPCs between 0 and 84 days, and then the splitting tensile strength decreased at a slower speed (compared to its increase) until 168 days, yet the splitting tensile strength dropped rapidly after 196 days. This result was accordant with the changing trends of porosity (Figure 2) and compressive strength (Figure 5) during the same erosion time. The reasons for the increase and decrease of splitting tensile strength were the same as those of compressive strength mentioned above.

The splitting tensile strength of HPC2, in general, was the highest before and after exposure to magnesium sulfate solution, which suggested that this kind of HPC had the strongest resistance to magnesium sulfate attack in terms of splitting tensile strength. In addition, the splitting tensile strength of HPC3 was lower than that of HPC0 after 224 days, which indicated that the sulfate attack resistance of HPC3 was lower than that of HPC0. In other words, with this content (30\%) of fly ash, the splitting tensile strength of HPC could be decreased slightly, the result of which was accordant with those of mass loss ratio (Figure 3 ) and compressive strength (Figure 5).

4.7. UPV. The UPV of HPCs before and after exposure to sulfate solution is presented in Figure 7.

As seen in Figure 7, the UPV of HPCs decreased continually with the increase of erosion time, and there was an accelerating process in the decrease of UPV after 308 days. This phenomenon corresponded broadly with the changing trends of the compressive strength (Figure 5) and splitting tensile strength (Figure 6), the result of which indicated that the deterioration of HPCs in terms of mechanical strengths could be evaluated by the means of UPV test. The decrease of UPV with the increase of erosion time was due to the damaged microstructure and the induced sulfate attack damage in HPCs.

After 308 days, the UPV of HPCs was decreased significantly, which suggested that there was a sharp rise in the degree of deterioration in HPCs. Furthermore, the UPV of HPC2 was the highest after 308 days, which indicated that this kind of HPC had the strongest resistance to magnesium sulfate attack in terms of UPV. It was worth noting that the UPV of HPC3 was lower than that of HPC0 before 308 days, which demonstrated that the sulfate attack resistance of HPC3 was lower than that of HPC0 during this period.

4.8. Relationships between Strengths and UPV. The relationships between strengths and UPV for HPCs are shown in Figure 8.

As illustrated in Figure 8(a), the compressive strength of HPCs increased quickly and then there was a slight fall with the increase of UPV, and their compressive strength evolution was accordant, the result of which could be described by a polynomial fitting, as the full line in Figure 8(a). The equation of the polynomial was shown as follows:

$$
\begin{aligned}
f_{\mathrm{cs}}= & 197.28883-142.24795 \mathrm{~V}+44.76914 V^{2} \\
& -4.20657 \mathrm{~V}^{3}
\end{aligned}
$$

where $f_{\text {cs }}$ is the compressive strength of HPCs and $V$ is the UPV propagation in HPCs.

Similar to compressive strength, the splitting tensile strength of HPCs also increased sharply and then decreased slightly with the increase of UPV, as shown in Figure 8(b). Their splitting tensile strength evolution was consistent, and the results suggested that a polynomial relationship could provide an approximation to assess the splitting tensile strength of HPCs via UPV. The following was the expression of the polynomial:

$$
\begin{aligned}
f_{\text {sts }}= & 18.56919-13.69795 V+4.24942 V^{2} \\
& -0.39801 V^{3}
\end{aligned}
$$

where $f_{\text {sts }}$ is the splitting tensile strength of HPCs.

The $R$-Square of the polynomial fitting for compressive strength and splitting tensile strength was 0.9587 and 0.9684 , respectively, which indicated that the fitting results matched rather well with the experimental data and that (9) and (10) could be used to evaluate the compressive strength and the splitting tensile strength of HPCs by UPV. In addition, the relationships between mechanical strengths and UPV of HPCs were different from those of ferro-siliceous concretes, and the compressive strength-UPV and splitting tensile strength-UPV relationships of ferro-siliceous concretes were Weibull distribution and exponential form, respectively [34]. Maybe that was because the deterioration of ferro-siliceous concretes was due to high temperature. 


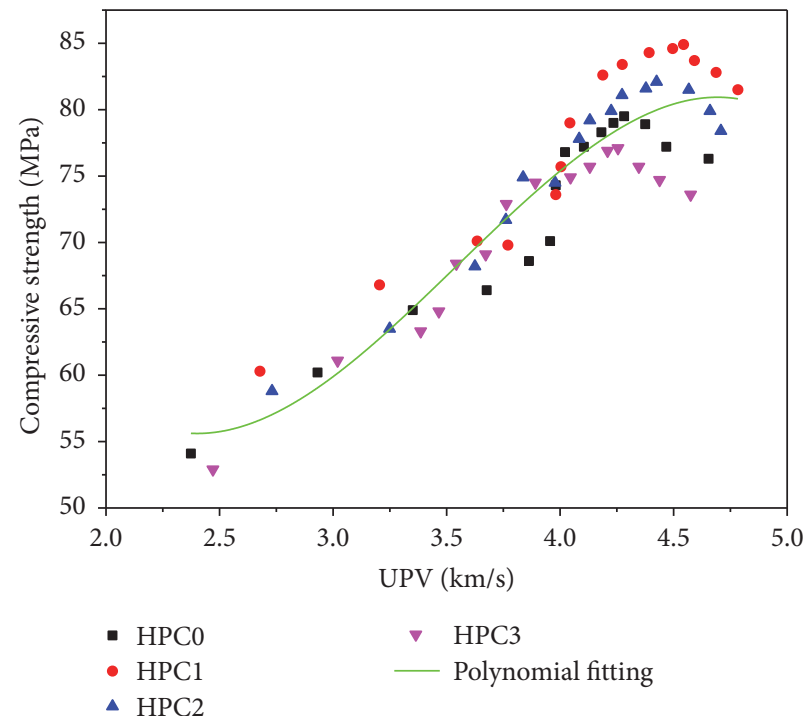

(a)

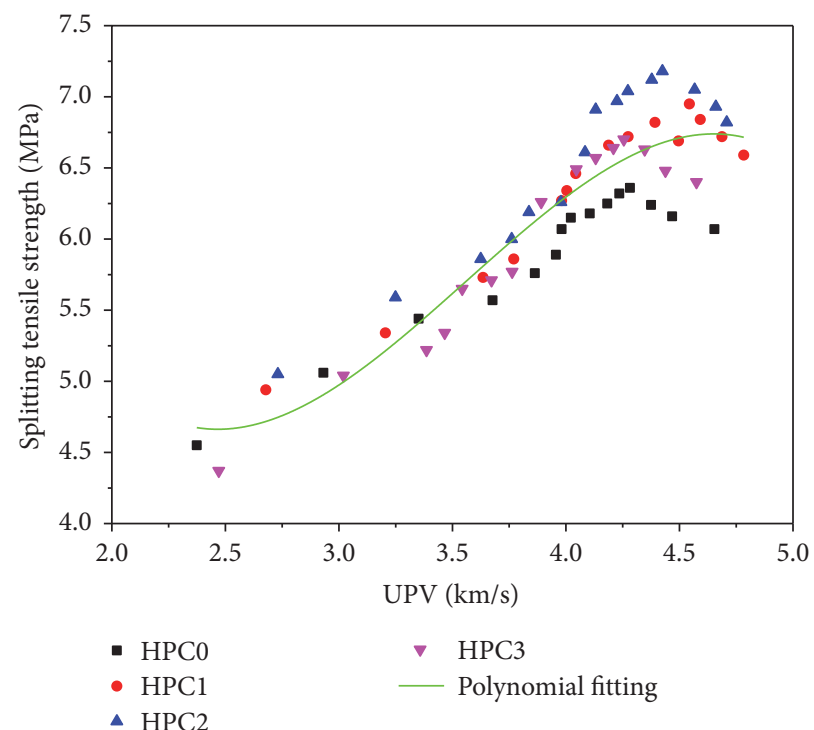

(b)

FIGURE 8: Relationships between strengths and UPV for HPCs: (a) compressive strength versus UPV and (b) splitting tensile strength versus UPV.

It should be emphasized that the empirical formulas might not precisely predict the mechanical strengths (both compressive and splitting tensile strength) of HPCs with different compositions, such as different mineral admixtures, different aggregate types, and different water to binder ratio. On the whole, however, the models established in the paper were remarkably accurate to assess the mechanical strengths of HPCs under magnesium sulfate attack. In practice, the empirical models could provide a convenient way to evaluate mechanical strengths of HPCs subjected to magnesium sulfate environment.

4.9. Damage. According to Figures 3 and 4, both the mass loss ratio and expansion ratio of HPCs could be obtained. The initial density of HPCs could be calculated from (7). Based on these results, the density of HPCs at different erosion time could be determined, as shown in Figure 9. Therefore, the damage of HPCs at various erosion time could be calculated through (6) and is plotted in detail in Figure 10.

As illustrated in Figure 9, the density of HPCs increased firstly and then decreased with the increment of erosion time, and a maximum value was reached at 84 days. This changing trend was accordant well with those of the porosity (Figure 2), the mass loss ratio (Figure 3), the compressive strength (Figure 5), and the splitting tensile strength (Figure 6). The phenomenon of density gain for HPCs is in line with the results of high strength self-consolidating concrete under magnesium sulfate attack [1]. The density gain could be attributed to water filling cracks and to the water used to precipitate the hydrated phase, such as ettringite [29]. In addition, the density of HPCs was important input data for the calculation of their damage.

As shown in Figure 10, the damage of HPCs increased sharply with the increase of erosion time. The damage of

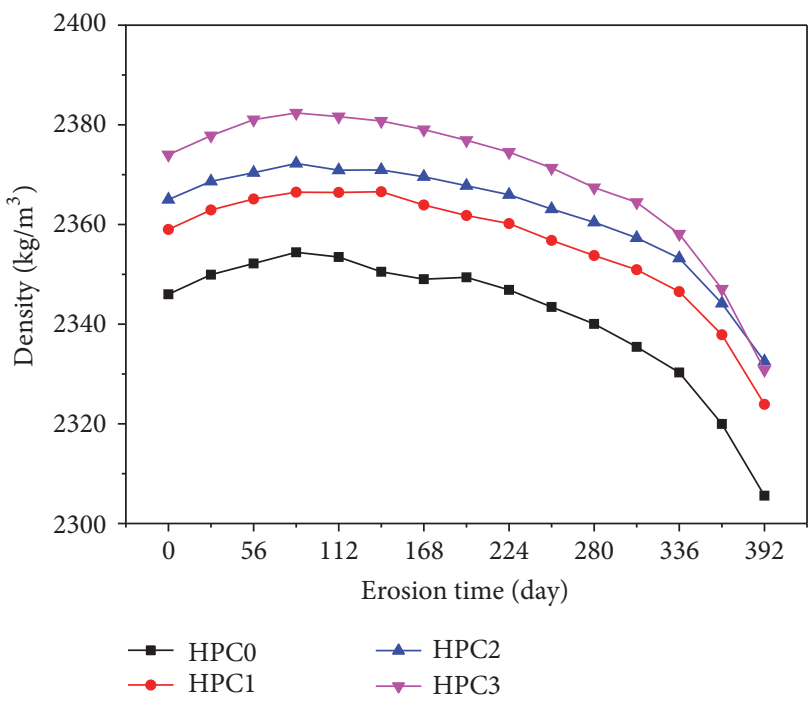

Figure 9: Density of HPCs at different erosion time.

HPC2 was broadly the lowest before and after exposure to magnesium sulfate solution, which suggested that this kind of HPC had the strongest resistance to magnesium sulfate attack in terms of damage. When HPCs were exposed to magnesium sulfate solution, their damage evolution was accordant and could be described by an exponential fitting (the full curve in Figure 10). The exponential model could be expressed by an equation as follows:

$$
D=0.11881 e^{0.00464 T}-0.07298,
$$

where $D$ is the damage of HPCs and $T$ is the erosion time of HPCs. 


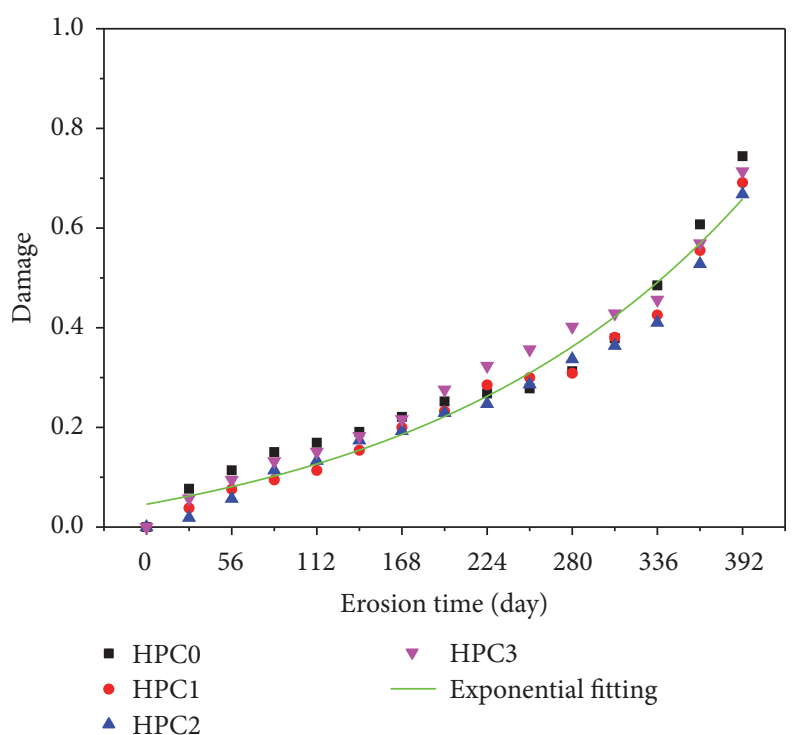

FIGURE 10: Damage of HPCs at various erosion time.

The $R$-Square of the exponential fitting was 0.9629 , which indicated that the fitting result agreed very well with the experimental data and that (11) could be applied to characterize the damage evolution of HPCs under magnesium sulfate attack. It should be stressed that the damage of HPCs increased slowly between 0 and 84 days, which matched well with the changing trend of UPV (Figure 7) in the same term, but accorded not so well with the changing trends of porosity (Figure 2), compressive strength (Figure 5), and splitting tensile strength (Figure 6) during the same period. And different form of damage evolution was also reported by other researchers, such as Weibull distribution model [35]. These results might slightly jeopardize the damage assessment. On the whole, however, the model established in the study was reasonably precise to describe the damage evolution HPCs under magnesium sulfate attack. In practice, the established model could be utilized in damage assessment of HPCs and evaluation of magnesium sulfate attack.

In summary, $\mathrm{HPCl}$ and $\mathrm{HPC} 2$ had the stronger resistance to magnesium sulfate attack than that of HPCO and HPC3. Furthermore, compared to HPC1, HPC2 was shown to has higher porosity, lower mass loss ratio, lower expansion ration, lower compressive strength, higher splitting tensile strength, and lower damage. Consequently, the HPC2, on the whole, had the strongest resistance to magnesium sulfate attack.

\section{Conclusions}

In the paper, a new kind of HPC that has characteristics of both high strength concrete and self-consolidating concrete is designed, and the mechanical properties and damage evolution of HPC with different contents of fly ash under magnesium sulfate attack are comprehensively investigated. The main conclusions drawn in this study are as follows:

(1) The porosity of HPCs decreases slowly before a sharp rise with the increase of erosion time, and the porosity reaches the minimum value at 84 (HPC3) or 112 (HPC0, HPC1, and HPC2) days. The average increasing amplitude of porosity for HPCs is $34.01 \%$ before and after exposure to $10 \%$ magnesium sulfate solution. HPC1 has the strongest resistance to magnesium sulfate attack in terms of porosity.

(2) The mass loss ratio of HPCs decreases firstly and then increases with the increment of erosion time, and a minimum value is reached at 84 days. The mass loss ratio of HPCs, as a whole, is about between $-0.25 \%$ and $1.60 \%$. HPC2 has the strongest resistance to magnesium sulfate attack in terms of mass loss ratio.

(3) The expansion ratio of HPCs decreases quickly and then increases rapidly with the increase of erosion time, and the expansion ratio reaches the minimum value at 84 (HPC0, HPC2, and HPC3) or 112 (HPC1) days. Overall, the expansion ratio of HPCs is approximately between $-0.45 \%$ and $0.96 \%$. HPC2 has the strongest resistance to magnesium sulfate attack in terms of expansion ratio.

(4) The compressive strength of HPCs increases firstly and then decreases with the increment of erosion time, and a maximum value is reached at 84 days. $\mathrm{HPCl}$ has the strongest resistance to magnesium sulfate attack in terms of compressive strength.

(5) The splitting tensile strength of HPCs increases firstly and then decreases with the increase of erosion time, and a maximum value is reached at 84 days. HPC2 has the strongest resistance to magnesium sulfate attack in terms of splitting tensile strength.

(6) The UPV of HPCs decreases continually with the increase of erosion time, and there is an accelerating process in the decrease of UPV after 308 days. HPC2 has the strongest resistance to magnesium sulfate attack in terms of UPV.

(7) The relationships between mechanical strengths and UPV for HPCs can be described by 2 polynomial fittings. In practice, the empirical models can provide a convenient way to evaluate mechanical strengths of HPCs subjected to magnesium sulfate environment.

(8) The damage of HPCs increases sharply with the increase of erosion time and can be described by an exponential fitting. In practice, the established model can be utilized in damage assessment of HPCs and evaluation of magnesium sulfate attack. HPC2 has the strongest resistance to magnesium sulfate attack in terms of damage.

\section{Conflicts of Interest}

The authors declare that there are no conflicts of interest regarding the publication of this paper. 


\section{Acknowledgments}

The research is financially supported by Scientific Research Project of the Education Department of Zhejiang Province of China (no. Y201327450), the Zhejiang Open Foundation of the Most Important Subjects (nos. zj1208 and zj1209), and Scientific Research Project of Jiangsu Provincial Department of Housing and Urban-Rural Development (no. 094828867208), which are gratefully appreciated.

\section{References}

[1] H. Siad, M. Lachemi, S. K. Bernard, M. Sahmaran, and A. Hossain, "Assessment of the long-term performance of SCC incorporating different mineral admixtures in a magnesium sulphate environment," Construction and Building Materials, vol. 80, pp. 141-154, 2015.

[2] K. Yildirim and M. Sumer, "Effects of sodium chloride and magnesium sulfate concentration on the durability of cement mortar with and without fly ash," Composites Part B: Engineering, vol. 52, pp. 56-61, 2013.

[3] E. E. Hekal, E. Kishar, and H. Mostafa, "Magnesium sulfate attack on hardened blended cement pastes under different circumstances," Cement and Concrete Research, vol. 32, no. 9, pp. 1421-1427, 2002.

[4] D. D. Higgins, "Increased sulfate resistance of ggbs concrete in the presence of carbonate," Cement and Concrete Composites, vol. 25, no. 8, pp. 913-919, 2003.

[5] D. Bonen and M. D. Cohen, "Magnesium sulfate attack on portland cement paste-I. Microstructural analysis," Cement and Concrete Research, vol. 22, no. 1, pp. 169-180, 1992.

[6] D. Bonen and M. D. Cohen, "Magnesium sulfate attack on portland cement paste - II. Chemical and mineralogical analyses," Cement and Concrete Research, vol. 22, no. 4, pp. 707-718, 1992.

[7] C. Jaturapitakkul, K. Kiattikomol, W. Tangchirapat, and T. Saeting, "Evaluation of the sulfate resistance of concrete containing palm oil fuel ash," Construction and Building Materials, vol. 21, no. 7, pp. 1399-1405, 2007.

[8] M. Sumer, "Compressive strength and sulfate resistance properties of concretes containing Class F and Class C fly ashes," Construction and Building Materials, vol. 34, pp. 531-536, 2012.

[9] N. Chousidis, I. Ioannou, E. Rakanta, C. Koutsodontis, and G. Batis, "Effect of fly ash chemical composition on the reinforcement corrosion, thermal diffusion and strength of blended cement concretes," Construction and Building Materials, vol. 126, pp. 86-97, 2016.

[10] D. Mostofinejad, F. Nosouhian, and H. Nazari-Monfared, "Influence of magnesium sulphate concentration on durability of concrete containing micro-silica, slag and limestone powder using durability index," Construction and Building Materials, vol. 117, pp. 107-120, 2016.

[11] P. K. Acharya and S. K. Patro, "Acid resistance, sulphate resistance and strength properties of concrete containing ferrochrome ash (FA) and lime," Construction and Building Materials, vol. 120, pp. 241-250, 2016.

[12] J. A. Jain and N. Neithalath, "Chloride transport in fly ash and glass powder modified concretes-influence of test methods on microstructure," Cement and Concrete Composites, vol. 32, no. 2, pp. 148-156, 2010.

[13] M. Uysal and M. Sumer, "Performance of self-compacting concrete containing different mineral admixtures," Construction and Building Materials, vol. 25, no. 11, pp. 4112-4120, 2011.
[14] H. Vikan and H. Justnes, "Rheology of cementitious paste with silica fume or limestone," Cement and Concrete Research, vol. 37, no. 11, pp. 1512-1517, 2007.

[15] K. Behfarnia and O. Farshadfar, "The effects of pozzolanic binders and polypropylene fibers on durability of SCC to magnesium sulfate attack," Construction and Building Materials, vol. 38, pp. 64-71, 2013.

[16] D. Harbec, A. Zidol, A. Tagnit-Hamou, and F. Gitzhofer, "Mechanical and durability properties of high performance glass fume concrete and mortars," Construction and Building Materials, vol. 134, pp. 142-156, 2017.

[17] J.-K. Chen and M.-Q. Jiang, "Long-term evolution of delayed ettringite and gypsum in Portland cement mortars under sulfate erosion," Construction and Building Materials, vol. 23, no. 2, pp. 812-816, 2009.

[18] M. Sahmaran, O. Kasap, K. Duru, and İ. Ö. Yaman, "Effects of mix composition and water-cement ratio on the sulfate resistance of blended cements," Cement and Concrete Composites, vol. 29, no. 3, pp. 159-167, 2007.

[19] O. S. B. Al-Amoudi, "Attack on plain and blended cements exposed to aggressive sulfate environments," Cement and Concrete Composites, vol. 24, no. 3-4, pp. 305-316, 2002.

[20] R. S. Gollop and H. F. W. Taylor, "Microstructural and microanalytical studies of sulfate attack. I. Ordinary portland cement paste," Cement and Concrete Research, vol. 22, no. 6, pp. 1027$1038,1992$.

[21] Y.-S. Park, J.-K. Suh, J.-H. Lee, and Y.-S. Shin, "Strength deterioration of high strength concrete in sulfate environment," Cement and Concrete Research, vol. 29, no. 9, pp. 1397-1402, 1999.

[22] M. H. Rarani, M. R. M. Aliha, M. M. Shokrieh, and M. R. Ayatollahi, "Mechanical durability of an optimized polymer concrete under various thermal cyclic loadings-an experimental study," Construction and Building Materials, vol. 64, pp. 308-315, 2014.

[23] Q. Zhou, J. Hill, E. A. Byars, J. C. Cripps, C. J. Lynsdale, and J. H. Sharp, "The role of $\mathrm{pH}$ in thaumasite sulfate attack," Cement and Concrete Research, vol. 36, no. 1, pp. 160-170, 2006.

[24] X. Brunetaud, M.-R. Khelifa, and M. Al-Mukhtar, "Size effect of concrete samples on the kinetics of external sulfate attack," Cement and Concrete Composites, vol. 34, no. 3, pp. 370-376, 2012.

[25] H. Chu, J. Jiang, W. Sun, and M. Zhang, "Effects of graphene sulfonate nanosheets on mechanical and thermal properties of sacrificial concrete during high temperature exposure," Cement and Concrete Composites, vol. 82, pp. 252-264, 2017.

[26] H.-Y. Chu and J.-K. Chen, "The experimental study on the correlation of resistivity and damage for conductive concrete," Cement and Concrete Composites, vol. 67, pp. 12-19, 2016.

[27] China Association for Engineering Construction Standardization, Beijing: China Architecture \& Building (in Chinese), 2005.

[28] S. Murakami, Continuum Damage Mechanics: A Continuum Mechanics Approach to The Analysis of Damage And Fracture, Springer, Berlin, Germany, 2012.

[29] C. Cao, W. Sun, and H. Qin, "Analysis on strength and fly ash effect of roller-compacted concrete with high volume fly ash," Cement and Concrete Research, vol. 30, no. 1, pp. 71-75, 2000.

[30] A. Skaropoulou, K. Sotiriadis, G. Kakali, and S. Tsivilis, "Use of mineral admixtures to improve the resistance of limestone cement concrete against thaumasite form of sulfate attack," Cement and Concrete Composites, vol. 37, no. 1, pp. 267-275, 2013. 
[31] Y. Maltais, E. Samson, and J. Marchand, "Predicting the durability of Portland cement systems in aggressive environments Laboratory validation," Cement and Concrete Research, vol. 34, no. 9, pp. 1579-1589, 2004.

[32] A. Neville, "The confused world of sulfate attack on concrete," Cement and Concrete Research, vol. 34, no. 8, pp. 1275-1296, 2004.

[33] B. Tian and M. D. Cohen, "Does gypsum formation during sulfate attack on concrete lead to expansion?" Cement and Concrete Research, vol. 30, no. 1, pp. 117-123, 2000.

[34] H. Chu, J. Jiang, W. Sun, and M. Zhang, "Mechanical and physicochemical properties of ferro-siliceous concrete subjected to elevated temperatures," Construction and Building Materials, vol. 122, pp. 743-752, 2016.

[35] H.-Y. Chu, J.-Y. Jiang, W. Sun, and M. Zhang, "Thermal behavior of siliceous and ferro-siliceous sacrificial concrete subjected to elevated temperatures," Materials and Design, vol. 95, pp. 470480, 2016. 

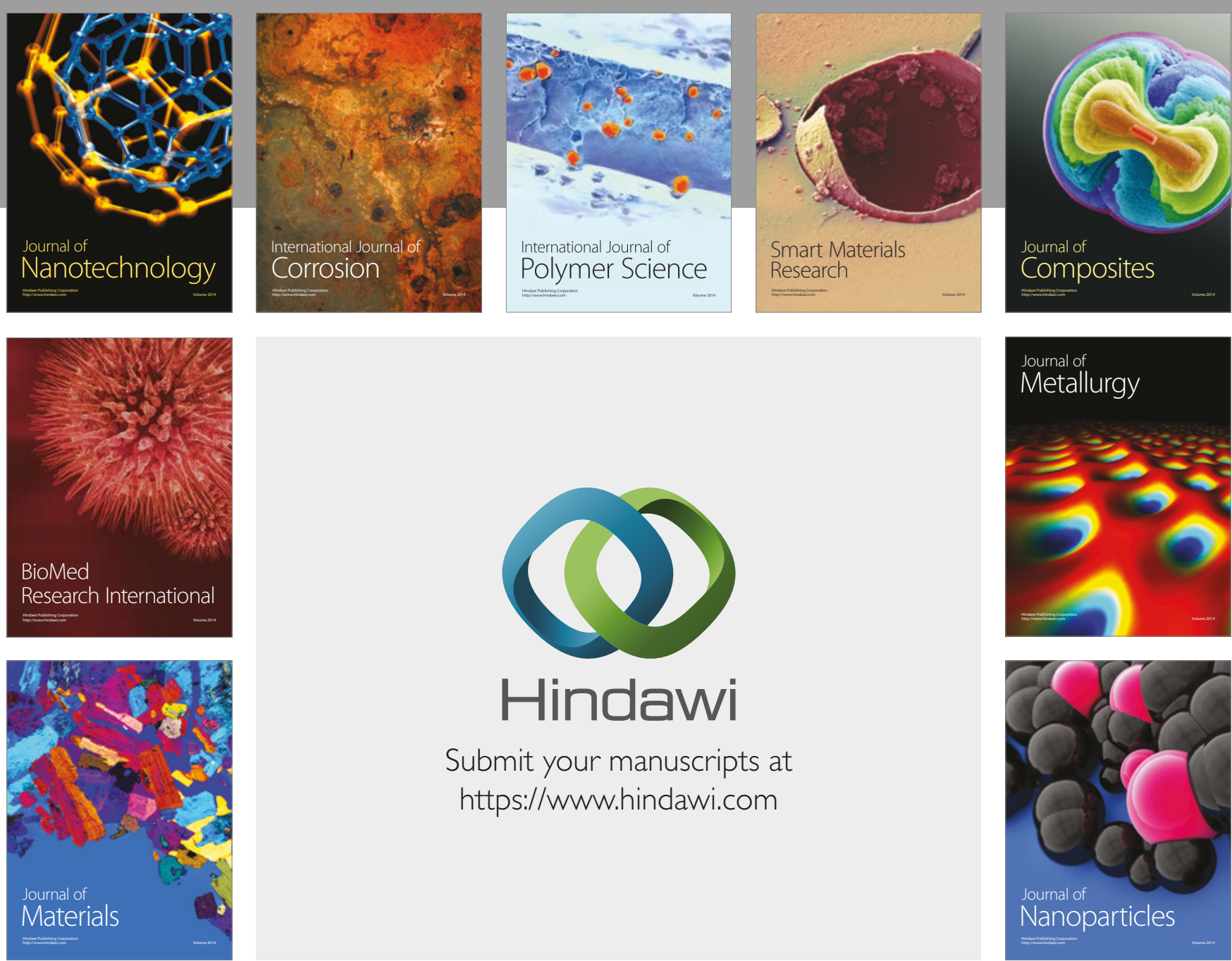

\section{Hindawi}

Submit your manuscripts at

https://www.hindawi.com
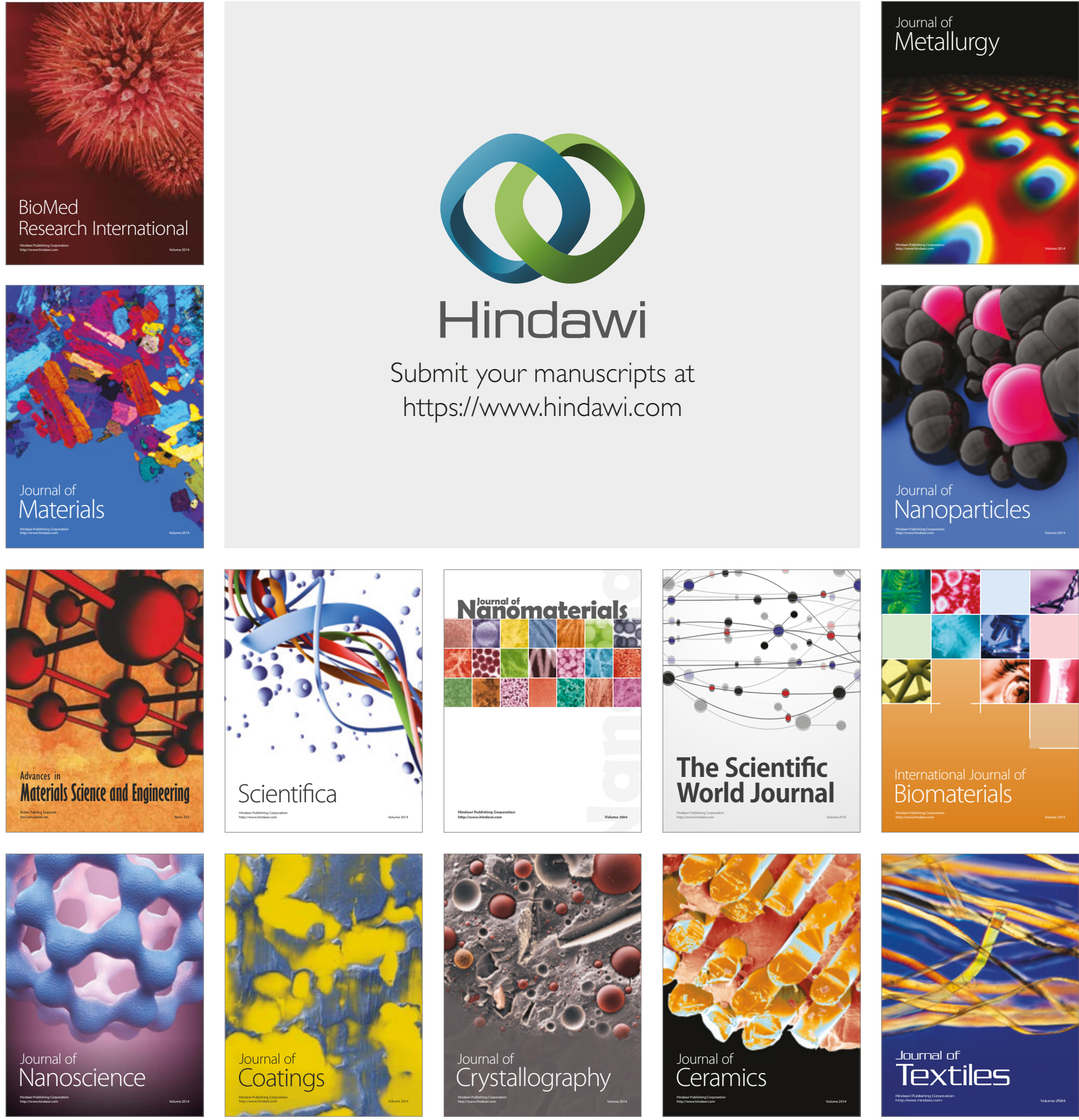

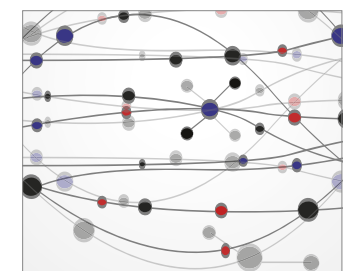

The Scientific World Journal
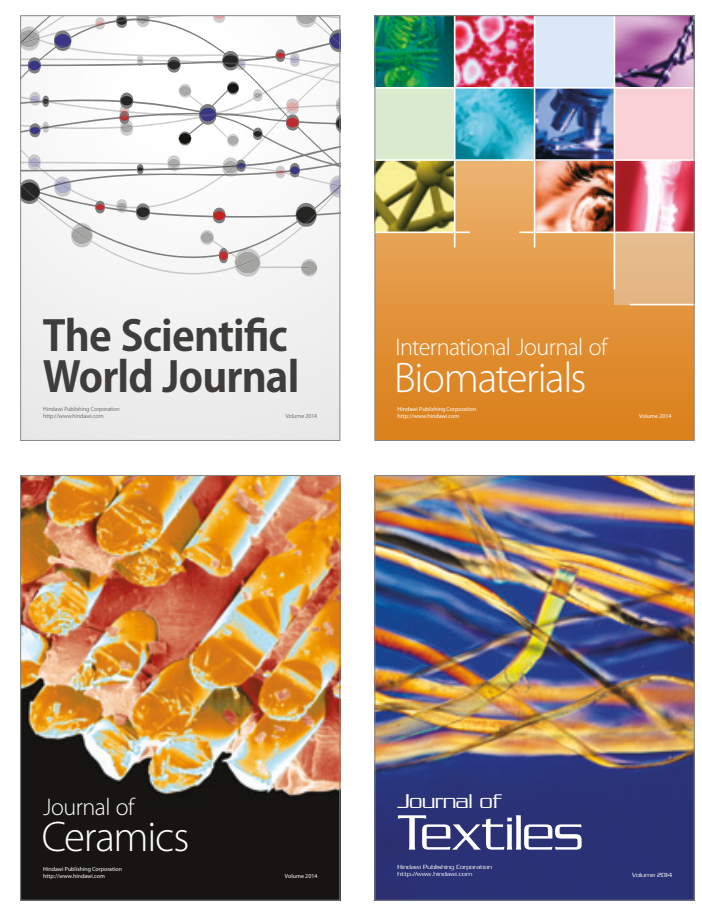